\title{
INDUSTRIAL CHEMISTRY OF THE LOWER OLEFINES
}

$\mathrm{E}$ VERY year Manchester is fortunate in having a symposium under the joint auspices of the Chemical Society, the Institute of Petroleum, the Royal Institute of Chemistry, and the Society of Chemical Industry. The symposium, held on March 24, entitled "The Industrial Chemistry of the Lower Olefines", and organized by the Institute of Petroleum, fully maintained the high standards set in earlier years.

It is good to take stock periodically, and this symposium was essentially an appraisal of the current position relating to the compounds ethylene, propylene, butadiene and ethylene oxide, and to the methods more recently available for the conver. sion of simple olefines to polymers of technical importance. There were no startling new revelations, but such are not expected in a stocktaking process.

The symposium was divided into a morning and afternoon session, each of two lectures, and an early evening session of one lecture. The morning session, under the chairmanship of Prof. F. Morton, began with a detailed and useful paper by $J$. Chrones and J. L. James (Kellogg International Corporation) entitled "The Economies of Ethylene Production from Light Naphtha". Without the knowledge that the preprint of his paper had been issued in advance, it would have been quite impossible for Mr. Chrones to have presented verbally the wealth of detail and calculation in his paper within the time available. It was predicted that in regions such as Britain, where natural gas is not available, light naphtha will continue to be the favoured raw material for the production of ethylene by steam cracking. Light naphtha is available readily and at a relatively low price; this price and the value of the cracking products other than ethylene (for example, propylene, butadiene, gasoline, fuel oil) form the main factors affecting the economics of ethylene imanufacture. These economics were considered for three types of light naphtha pyrolysis units designed to yield 100 millions of pounds per annum of polymer-grade ethylene of 99.9 per cent purity: (a) high-severity pyrolysis with recycle of ethane product to pyrolysis, thus minimizing feed consumption, and favoured when the cost of light naphtha is high, (b) medium severity pyrolysis with recycle of ethane to pyrolysis, and $(c)$ medium severity pyrolysis without recycle of othane, this being preferred when the light naphtha cost is low or the value of the by-products is high. Under present conditions the demand for ethylene as a petrochemical considerably outweighs that for the other by-products; pyrolysis under conditions favouring a high ratio of propylene to ethylene thus cannot be justified, since enough propylene is obtained as by-product under high-severity pyrolysis conditions to satisfy completely the increasing demand for propylene for conversion to polypropylene.

Numerous articles have appeared on the manufacture of ethylene oxide, and it is a credit to Dr. R. P. van Oosten (Bataafse Internationale Chemi Maatschappij) that his approach to the subject "The Production of Ethylene Oxide", and the style and delivery of his lecture, were refreshingly original. Two processes are of technical importance at the present time: the chlorohydrin method, and the one-step direct oxidation using oxygen in presence of a silver catalyst. In 1955 some 55 per cent of the ethylene oxide in the United States was prepared by the chlorohydrin route; in 1960 only 40 per cent will be so prepared. New producers of ethylene oxide thus prefer the direct oxidation route, and the older chlorohydrin plants are often being used for the production of propylene oxide, a chemical of increasing importance, and one for which no satisfactory direct oxidation process from propylene at present exists. The chlorohydrin method for ethylene oxide production gives a better overall yield, but suffers from two major disadvantages : chlorine is required, and increase in chlorine produetion aggravates the growing unbalance between chlorine and caustic soda production; furthermore, by-product ethylene dichloride and waste-product calcium chloride have to be disposed of. Most of the engineering difficulties at one time apparent in the direct oxidation process have now been simplified or solved, and the facts that concentrated ethylene, necessary for direct oxidation, is becoming a relatively cheap chemical, and that the yields of ethylene oxide and the life of the silver catalyst steadily increase, emphasize still more the reasons for the emergenee of the direct oxidation route as the preferred method. With a total consumption in the United States of 910 millions of pounds per annum in 1955 rising to an estimated total of 1,250 millions of pounds per annum in 1960 , and 1,800 millions of pounds per annum in 1965 , few chemicals have a brighter future than ethylene oxide.

The afternoon session, under the chairmanship of Prof. R. N. Haszeldine, got off to a good start with the paper by Dr. A. F. Millidge (Distillers Co., Ltd.) on "Industrial Chemicals based on Ethylene and Propylene". 'This is an enormous topic and the paper was correspondingly by far the longest of the sym. posium. The main lessons to be learned from this detailed review were, first, the versatility of ethylene and propylene in providing industrial raw materials and, second, that even to-day it is still possible to discover quite new reactions and technical processes. Formation of acrylonitrile by reaction of propylene with ammonia and air ; direct oxidation of ethylene to acetaldehyde; preparation of ethyl acetate in 98 per cent yield directly from acetaldehyde; conversion of propylene into acrylonitrile by use of nitric oxide ; oxidation of isopropyl alcohol to acetone and hydrogen peroxide, provide typical examples.

The next paper, by Mr. A. A. Appleton (Esso Petroleum Co., Ltd.), was entitled "Production and Utilization of Butadiene". It reviewed first the historical development of butadiene as a petrochemical, then dealt with methods of preparation. Particular attention was paid to routes involving catalytic dehydrogenation of the butenes. Steam, used as diluent, provides a medium which both carries heat to the catalyst bed and simultaneously lowers the butene partial pressure--very necessary if polymerization and ultimate degradation of butadiene to coke and hydrogen are to be avoided. Several types of catalyst were compared, the most selective being a 
calcium nickel phosphate stabilized with chromium oxide. Conversions of butenes to butadiene of 30-50 per cent can be obtained with a selectivity of approximately 90 per cent. Other catalysts, for example, one containing ferric oxide, chromium oxide and potas. sium oxide, are less selective at higher conversions, but require a lower steam dilution ratio and have longer life.

The direct dehydrogenation of $n$-butane to butadiene is being used at five of the more recent butadiene plants. A particular advantage of this process, employing a catalyst of activated alumina with 18-20 per cent of chromic oxide, is that it can be used to make butadiene or a mixture of butadiene and butenes. The present position in Europe is such that supplies of butenes from refinery catalytic cracking are inadequate, and emphasis has been placed, for example, in Germany, on butane dehydrogenation; the European figures for butadiene (18 per cent from butenes, 22 per cent from $n$-butane, 38 per cent from steam cracking of light naphtha and 22 per cent from acetylene), are quite different from the corresponding figures from the United States $(48,41,11$ and 0 per cent, respectively). The heavy European dependence on steam cracking is associated with the considerable ethylene production capacity based on this route, and this position is unlikely to change for some time, although additional butadiene plants will need to be built to cope with the demand for SBR rubber.

Despite its versatility as a chemical, butadiene is too expensive an olefine compared with ethylene or propylene to find major outlet in anything but the polymer field; even acetylene is slightly less expensive. In the United States, 85 per cent of the butadiene is used in the manufacture of SBR rubber, with much smaller amounts (each 2 per cent) in the oil-resistant butadiene-acrylonitrile synthetic rubber, and in production of adiponitrile for nylon. Greatest growth-rate is offered by the polybutadiene rubber process, one involving stereospecific polymerization by Ziegler catalysts to a predominantly cis 1,4structure; this elastomer approaches natural rubber in properties although, unlike cis 1,4-polyisoprene, it must be used admixed with natural rubber.

The final symposium paper, "Newer Developments in the Polymerization of Olefines", was delivered by Prof. C. E. H. Bawn, with Prof. G. Gee in the chair. Prof. Bawn showed how a difficult, controversial and rapidly developing field of study, initiated by the now-classical work of Ziegler and Natta, could be summarized and presented in a clear and logical manner. The scientific significance and the commercial importance of the catalytic methods for the production of new classes of sterically regular polymers are apparent to everyone; seldom has one discovery had so rapid and enormous an impact on an industry. After surveying the Ziegler-type catalysts and the catalysts of the supported metal oxide type for the low-pressure polymerization of ethylene and other olefines, Prof. Bawn went on to discuss in masterly style the structures of the olefine and diene polymers and their properties. This paper brought to a close a most successful symposium. Interest in all the papers was high, and the audience had an appreciable number of questions to ask. Drs. H. Kaye, P. J. King and C. A. Curtis are to be congratulated on their organization; even Manchester provided blue skies for the occasion. The papers and discussion, which will appear in the Journal of the Institute of Petroleum, provide useful reading for all chemists and chemical engineers, since interest in the lower olefines extends far beyond the petroleum or petrochemicals industry. These compounds are the key building blocks of modern industrial organic chemistry.
R. N. HASZELDINE

\section{THE NATIONAL INSTITUTE OF GENETICS, JAPAN}

$I^{\mathbb{N}}$ 1949 the Institute of Genetics was set up in Japan to cover practically the whole range of this discipline. There are six departments devoted to morphological genetics, cytogenetics, physiological genetics, biochemical genetics, applied genetics, and induced mutation. In addition to these, the Rockefeller Foundation supports two groups of workers, one in special rice studies, and the other on the effects of radiation in animals.

Fifty-one research projects are being pursued in the six departments*. These range from virus, through insects (silkworms and drosophila) and plants to mammalia. They include such diverse topics as the cytology and genetics of tumours to studies of right- and left-handedness in plants. Radiation studies play a large part throughout the programme.

Many contributions deserve extended notice, though space will permit casual reference to only one or two of them.

An interesting paper is on the subject of a silkworm poison emanating from tobacco plants. It has long been known that when silkworm larvæ are fed

* National Institute of Geneties, Japan. Annual Report, No. 9 1958. Pp. $v+144$. (Misima, Sizuoka-ken: National Institute of Genetics, 1959 . on leaves taken from mulberry trees near a field of tobacco they are often poisoned. Tsujita and his co-workers now show that the poisonous substance is nicotine, which is present in mulberry leaves to the amount of 1-10 mgm. per kgm. When mulberry leaves were painted with diluted nicotine solutions of this order of concentration, silkworm larvæ showed similar symptoms of poisoning to those observed in the field. It is believed that nicotine molecules emanate from the tobacco plant secretions or from the disintegrating cells of the leaf hairs.

Cereal workers will note with interest the work of Oka and Sakai on the mode of inheritance of competitive ability in rice. They show that the competitive ability of a strain is determined genetically, and can be analysed by the same method as used for ordinary quantitative characters.

Differences in radiosensitivity and radiomutability between cultivated and wild strains of the Japanese morning glory were investigated by Kihara and Sakamoto. They report that both radiosensitivity and radiomutability of the cultivated strains was higher than in the wild one.

The number of papers published by the staff of the Institute was 108 in 1958, and 65 in 1957.

S. C. HARLANI 